\title{
Intraspinal primitive neuroectodermal tumors: Report of four cases and review of the literature
}

\author{
Jingyu Chen, Jinning Song, Hui Meng, Hua Feng \\ Department of Neurosurgery, Southwest Hospital, Third Military Medical University, Chongqing - 400 038, The People's Republic of China
}

Address for correspondence:
Dr. Feng Hua,
Department of Neurosurgery,
Southwest Hospital,
Third Military Medical University,
Chongqing 400 038, The People's
Republic of China.
E-mail: fenghua8888@yahoo.com.cn

PMID: 19934573

DOI: $10.4103 / 0028-3886.57804$

\begin{abstract}
Intraspinal primitive neuroectodermal tumors (PNETs) are extremely rare and are aggressive with poor outcomes. Till date only $4 \mathrm{I}$ cases of intraspinal PNET have been reported. Here we report four new cases. Total excision of the tumor was done in three patients and partial excision in one patient. The unusual clinical features were vertebral metasis in one patient and short history of symptoms for four dasy. All had surgical excision, total excision in three patients and gross partial excision in one patient. Three patients were treated with craniospinal radiotherapy and chemotherapy. All the four patients are alive and asymptomatic at 6 to 25 months of followup.
\end{abstract}

Key words: Chemotherapy, neurosurgery, primitive neuroectodermal tumor, spinal cord, radiotherapy

\section{Introduction}

As for the World Health Organization (WHO) classification of brain tumors, ${ }^{[1]}$ all undifferentiated (primitive) tumors are derived from common neuroepithelial cells and are thus classified under primitive neuroectodermal tumors (PNET). The undifferentiated or poorly differentiated neuroepithelial cells have the multipotent capability of differentiating into divergent lineages including neurons, astrocytes, ependymal cells, muscle cells or melanocytes. Hart and Earle were the first to introduce the term PENT in $1973{ }^{[2]}$ These tumors are more common in children. There is considerable confusion and controversy in the classification of PNETs. ${ }^{[3]}$ Central PNETs (cPNET) develop from the central nervous system (CNS) and peripheral PNETs (pPNET) putatively from the neural crest. ${ }^{[4]}$ This confusion may partly be due to overlap of CNS and peripheral nervous system at the spinal level. ${ }^{[5,6]}$ Both cPNET and pPNET, are aggressive tumors and have similar survival rates. However they differ in their clinical presentation and spread pattern. ${ }^{[5]}$ They also have distinct immunohistochemical profiles and clinical evolution and treatment protocols also differ. PNETs are mainly intracranial, predominantly in the cerebellum. ${ }^{[7]}$ Intraspinal PNETs are extremely rare. Only 41 cases have been reported in the literature till date. ${ }^{[5,6,8-35]}$ In this communication we report four cases of intraspinal PNET and also review literature on intraspinal PNET.

\section{Case Reports}

\section{Case 1}

A 19-year-old woman presented with right side neck pain and progressive weakness of all the four limbs of 45 days duration. She was bedridden five days before the admission. On examination, the motor power was grade $1 / 5$ in the right upper limb and grade $2-3 / 5$ in the remaining limbs. Magnetic resonance imaging (MRI) of the cervical spine revealed an extramedullary lesion extending from $\mathrm{C}_{4}$ to $\mathrm{C}_{7}$ vertebral level on the right side. The lesion was isointensity on T1-weighted image and hyperintensity on T2-weighted image [Figure 1a and b]. A provisional diagnosis of spinal meningioma was made. Through a $\mathrm{C}_{4}$-to- $\mathrm{C}_{7}$ laminectomy, a gross partial excision of the lesion was achieved [Figure 1c and d]. The tumor was soft, mauve, vascular and completely extramedullary in location, encasing a nerve root. Histopathological examination and immunohistochemical 


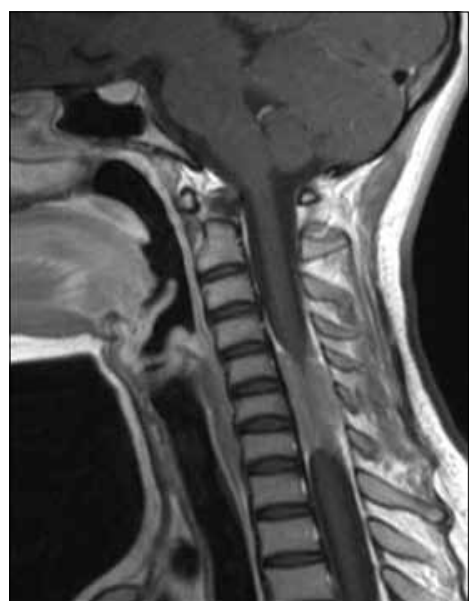

Figure 1a: Sagittal $(A, B)$ and axial $(C, D) T_{1}$-weighted magnetic resonance imaging of cervical spine showing partial excision of extramedullary lesion at $\mathrm{C4}-\mathrm{C} 7$

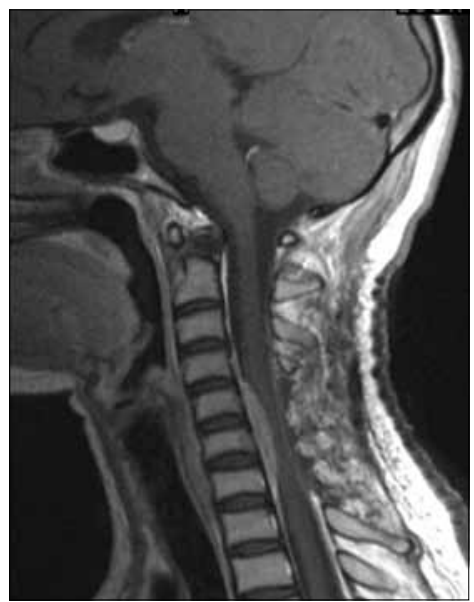

Figure 1c: Sagittal $(A, B)$ and axial $(C, D) T_{1}$-weighted magnetic resonance imaging of cervical spine showing partial excision of extramedullary lesion at $\mathrm{C} 4-\mathrm{C} 7$

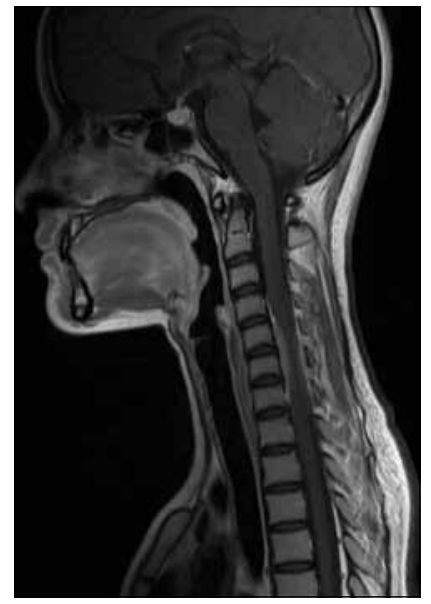

Figure 1e: Preoperative cranial magnetic resonance imaging showed that no other tumors were detected

staining confirmed the diagnosis of PNET. By the third postoperative week, the patient was ambulatory without support. She had six cycles of chemothotherapy consisting of cyclophosphamide and temozolomide, followed by

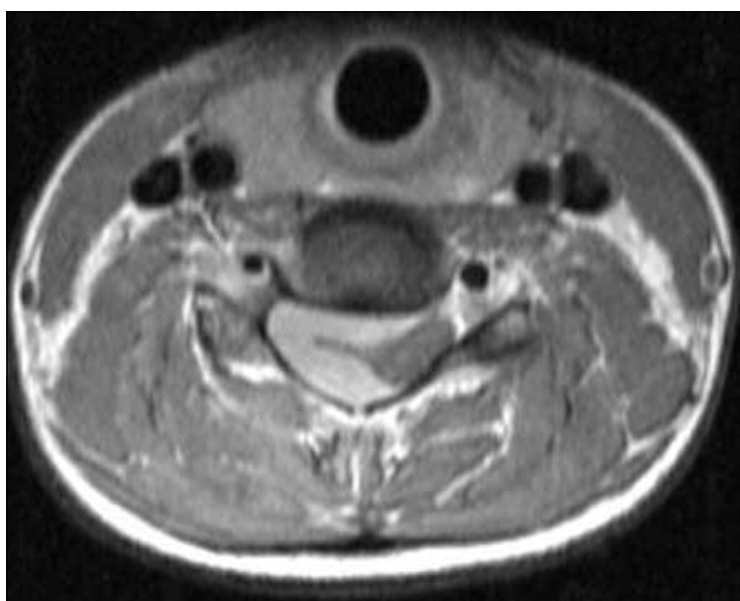

Figure 1b: Sagittal $(A, B)$ and axial $(C, D) T_{1}$-weighted magnetic resonance imaging of cervical spine showing partial excision of extramedullary lesion at C4-C7

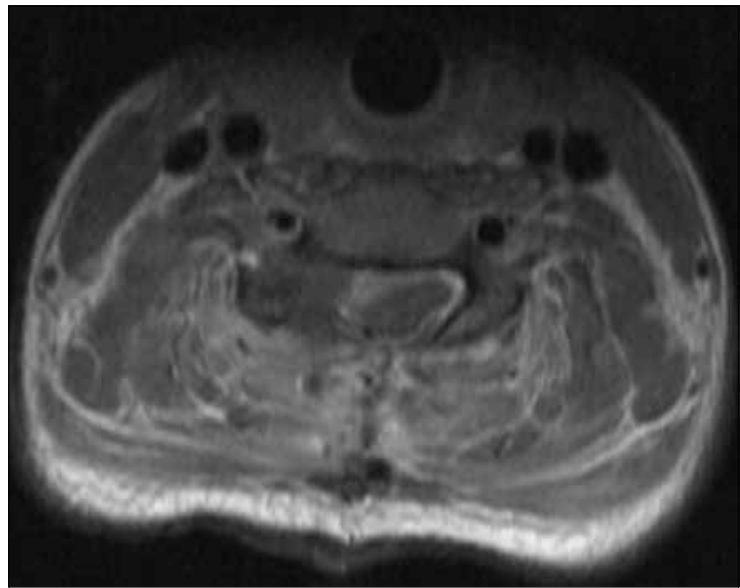

Figure 1d: Sagittal $(A, B)$ and axial $(C, D) T_{1}$-weighted magnetic resonance imaging of cervical spine showing partial excision of extramedullary lesion at $\mathrm{C} 4-\mathrm{C} 7$

cranio-spinal radiation therapy spread over eight weeks. She was alive at ten moths postoperatively.

\section{Case 2}

A 46-year-old man presented with a four-day history of progressive weakness of the lower limbs and urinary retention. On neurological examination, motor power was grade $3 / 5$ in the lower limbs, tendon reflexes were brisk and both the plantars were upgoing. He had hypoesthesia below $\mathrm{T}_{4}$ level. MRI of thoracic spine showed an intradural extramedullary tumor at the $\mathrm{T}_{1}-\mathrm{T}_{2}$ level compressing the cord [Figure 2a and b]. Preoperative cranial MRI and thorax and abdomen computerized tomography (CT) were negative for any tumor pathology. A laminectomy was performed at the $\mathrm{T}_{1}-\mathrm{T}_{2}$ vertebrae levels. At exploration, the intradural mass was subpial, soft grayish, adherent to the the spinal cord and encasing the nerve roots. A total excision was achieved. Postoperatively he had a partial improvement in the deficits. Histopathology and immunohistochemistry of the lesion revealed PNET [Figure $2 \mathrm{c}$ and d]. He received 


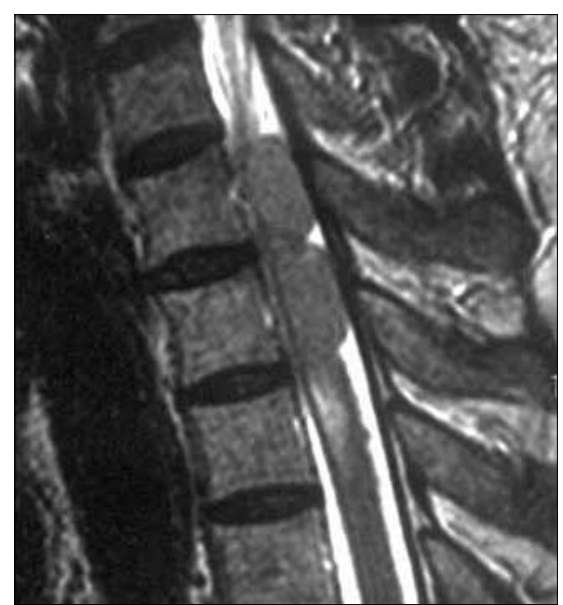

Figure 2a: Sagittal (A) and axial $(B) T_{1}$-weighted magnetic resonance imaging of preoperative extradural mass compressing the cord and infiltrating the paraspinal area through neural foramina

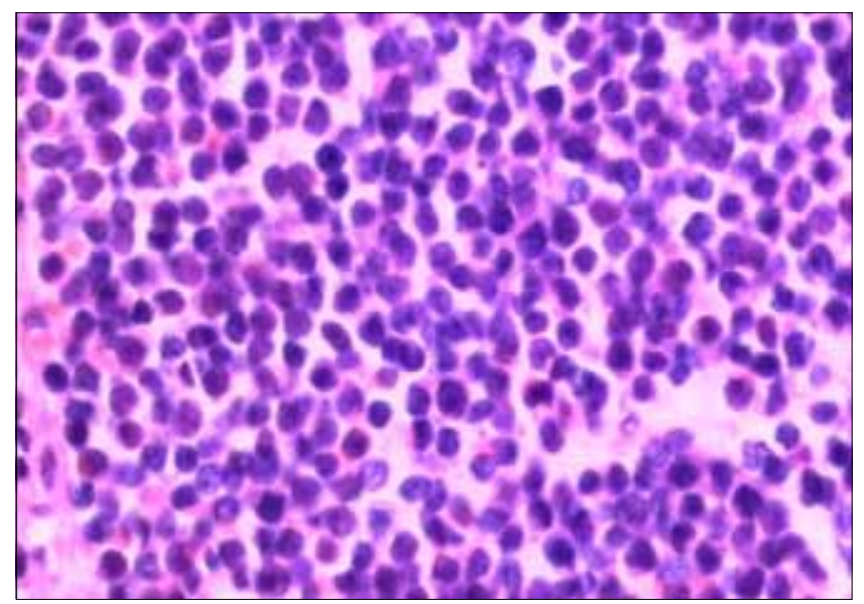

Figure 2c Micrographs of HE staining (D) and NSE

immunohistochemistry (E) in excised tumor tissue of case 2 patient showing undifferentiated small round cells with partly positive for CD99

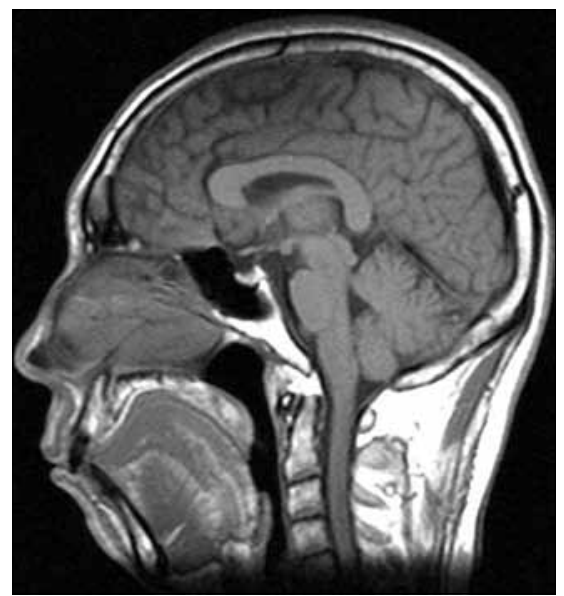

Figure 2e: Preoperative cranial magnetic resonance imaging showed that no other tumors were detected

chemotherapy consisting of vincristine, cyclophosphamide, and doxorubicin and also focal radiation therapy spread over a period of four weeks. There was no progression of the disease at the end of 14 months post-surgery.

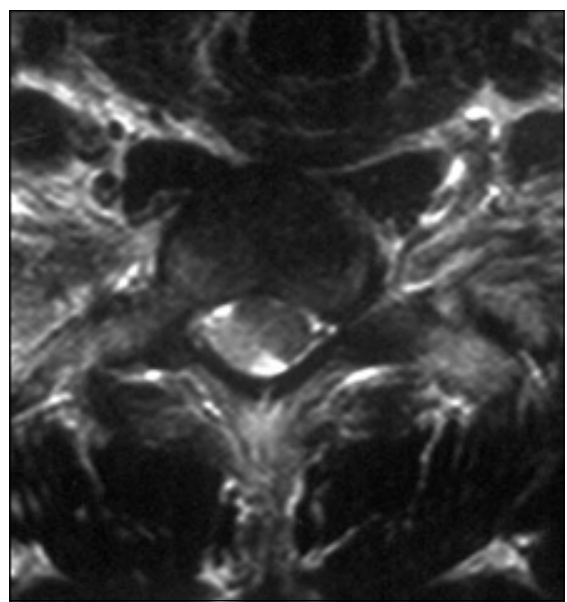

Figure 2b: Sagittal (A) and axial (B) $T_{1}$-weighted magnetic resonance imaging of preoperative extradural mass compressing the cord and infiltrating the paraspinal area through neural foramina

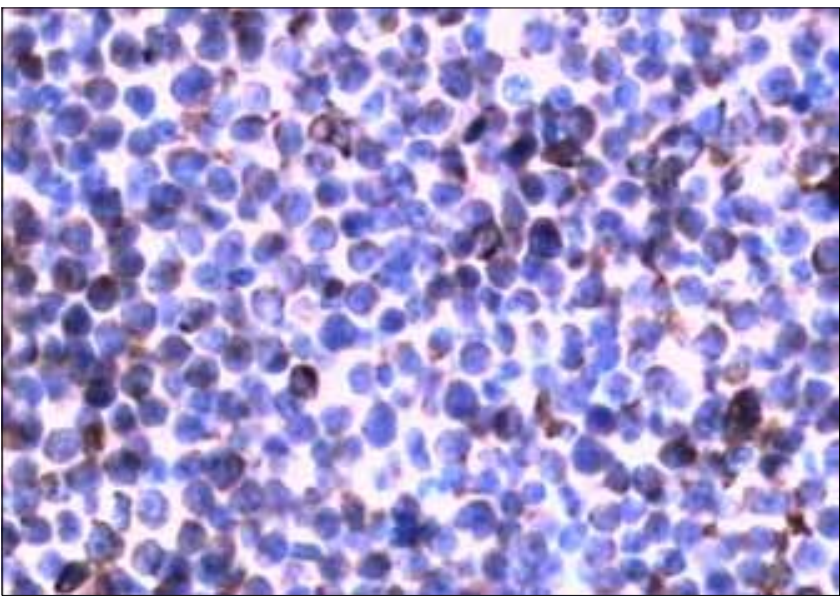

Figure 2d: Micrographs of HE staining (D) and NSE

immunohistochemistry (E) in excised tumor tissue of case 2 patient showing undifferentiated small round cells with partly positive for CD99

\section{Case 3}

A 58-year-old man presented with thoracic back pain of three months duration and progressive weakness of the lower limbs of 15 days duration. On neurological examination, motor power was grade $0 / 5$ in the lower limbs, tendon reflexes were pathological and both the plantars were upgoing. He had hypoesthesia below $\mathrm{T}_{3}$ level. MRI of the thoracic spine revealed a posterior intraspinal epidural lesion at the $\mathrm{T}_{4}$ level compressing the cord and several lesions in the body of the thorax vertebrae [Figure $3 a$ and $b$ ]. Positron emitted tomographycomputed tomography (PET-CT) of whole body showed metastasis to vertebrae [Figure 3f]. A laminectomy was performed from $T_{1}$ to $T_{2}$ and an epidurally located, capsulated mass, gray in color and without any adherence to the adjacent structures was totally excised [Figure $3 \mathrm{c}$ and $\mathrm{d}]$. The diagnosis of PNET was confirmed by histopathological and immunohistochemical examination [Figure $3 g$ and $h$ ]. During the early postoperative course, he had rapid neurological recovery and was able to walk 


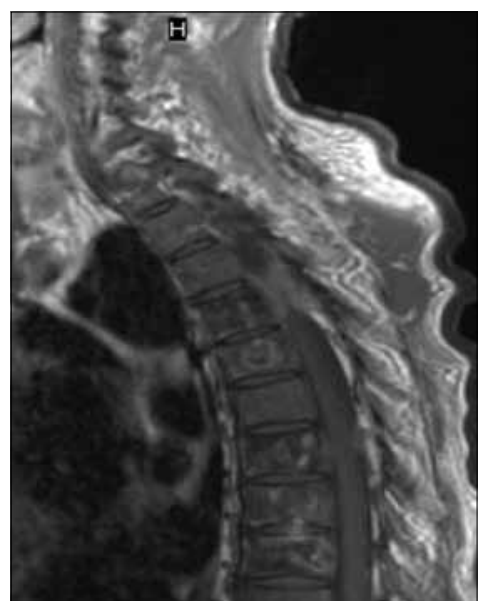

Figure 3a: Sagittal (A,B) and axial (C, D) T1-weighted magnetic resonance imaging of thoracic spine showing total excision of an intradural lesion with patchy contrast enhancement in $\mathrm{T}_{4}$ spinal cord, and the lesions on dorsal vertebrae

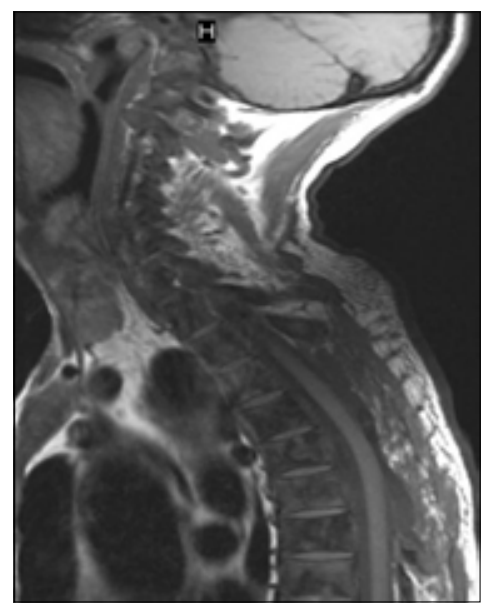

Figure 3c: Sagittal $(A, B)$ and axial $(C, D) T_{1}$-weighted magnetic resonance imaging of thoracic spine showing total excision of an intradural lesion

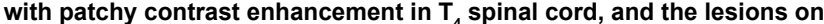
dorsal vertebrae

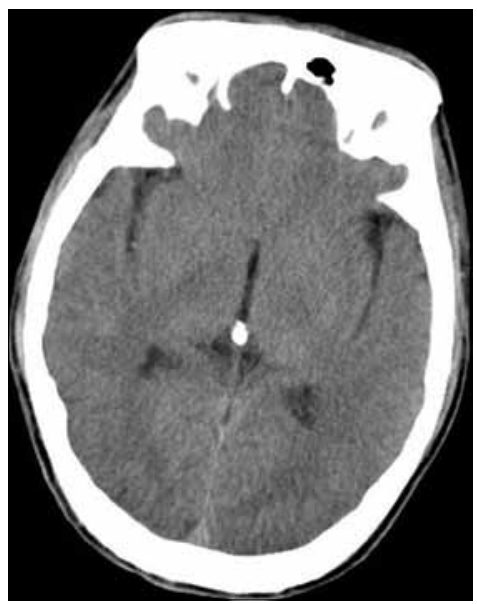

Figure 3e: Preoperative cranial computerized tomography showed that no other tumors were detected

unassisted. He did not receive any adjuvant therapy due to socioeconomic issues. He was alive at 25 months and remained alive in the $25^{\text {th }}$ month after operation.

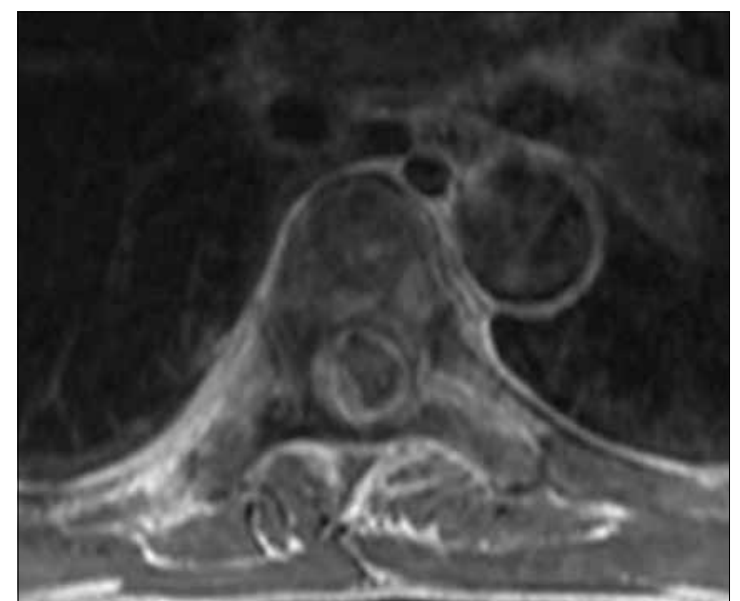

Figure 3b: Sagittal (A,B) and axial (C, D) $\mathrm{T}_{1}$-weighted magnetic resonance imaging of thoracic spine showing total excision of an intradural lesion with patchy contrast enhancement in $\mathrm{T}_{4}$ spinal cord, and the lesions on dorsal vertebrae

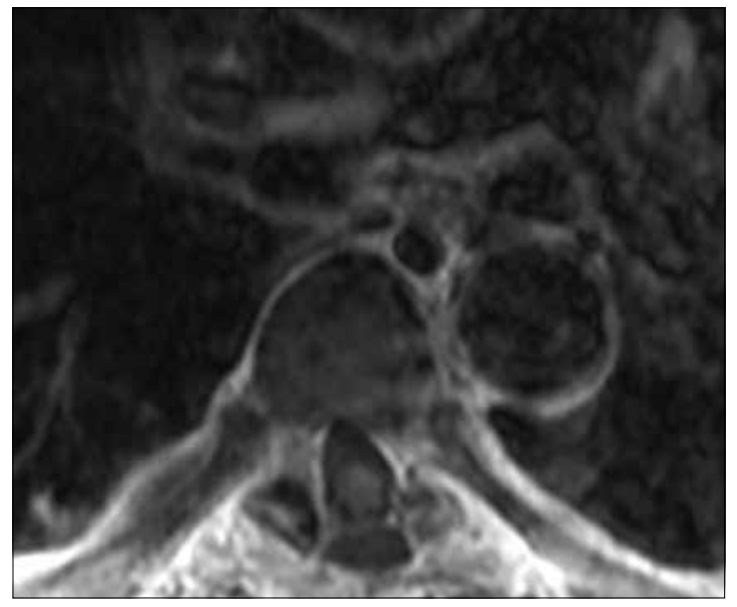

Figure 3d: Sagittal (A,B) and axial (C, D) $\mathrm{T}_{1}$-weighted magnetic resonance imaging of thoracic spine showing total excision of an intradural lesion with patchy contrast enhancement in $\mathrm{T}_{4}$ spinal cord, and the lesions on dorsal vertebrae

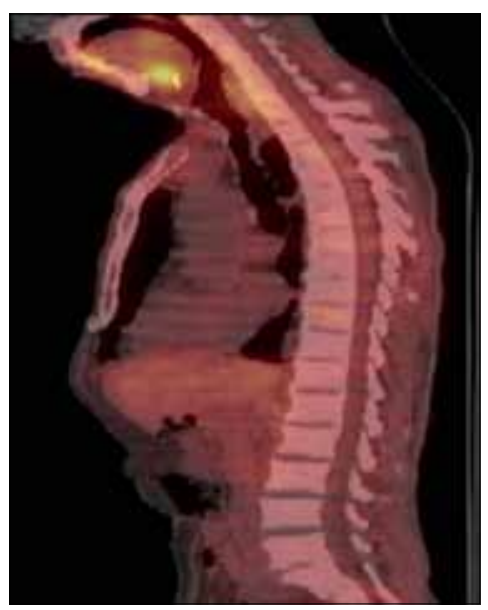

Figure 3f: Postoperative sagitta Positron emitted tomography-computed tomography showing abnormal metabolism of $T_{2}, T_{3}, T_{6}, T_{7}, T_{10}$ vertebraes but no abnormalities in other parts of body

\section{Case 4}

A 14-year-old boy presented with back pain and progressive weakness of both the lower limbs of four 


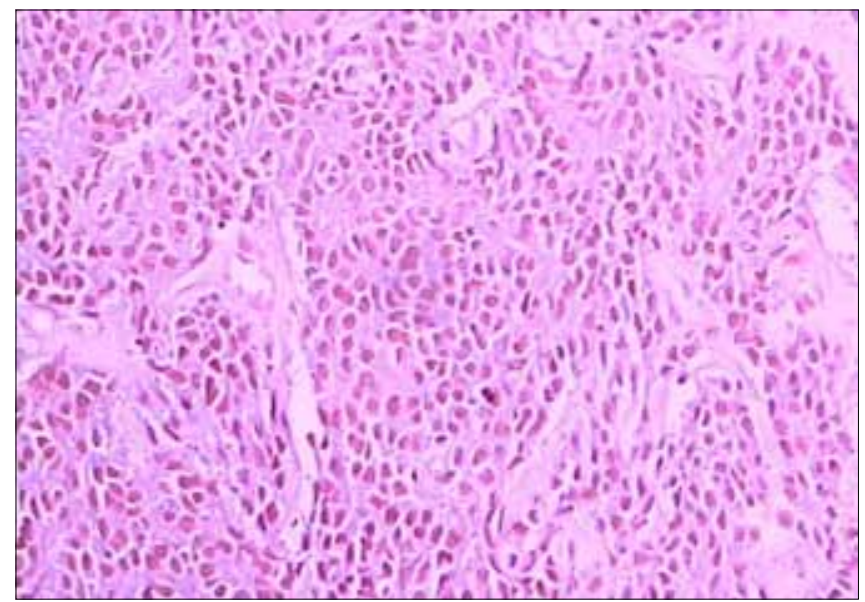

Figure 3g: Light microscopic photograph showing a typical highly cellular PPNET tumor consisting of undifferentiated small round cells with frequent mitoses(G) and CD99 immunoreactivity in pPNET tumor cells $(H)$.

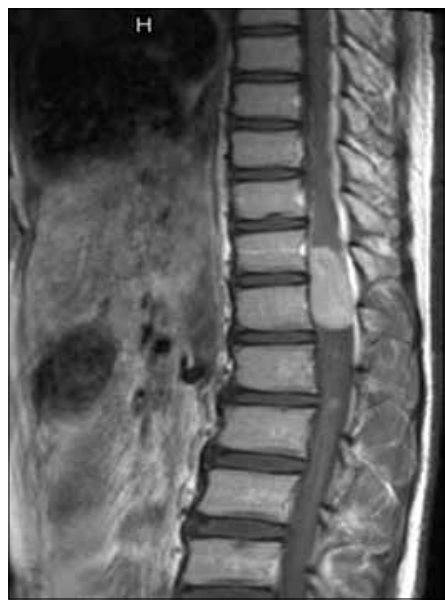

Figure 4a: Sagittal $(A, B)$ and axial $(C, D) T_{1}$-weighted magnetic resonance imaging of thoracic spine showing total excision of $T_{11}-T_{12}$ extradural mass compressing the cord and infiltrating the paraspinal area through the neural foramina

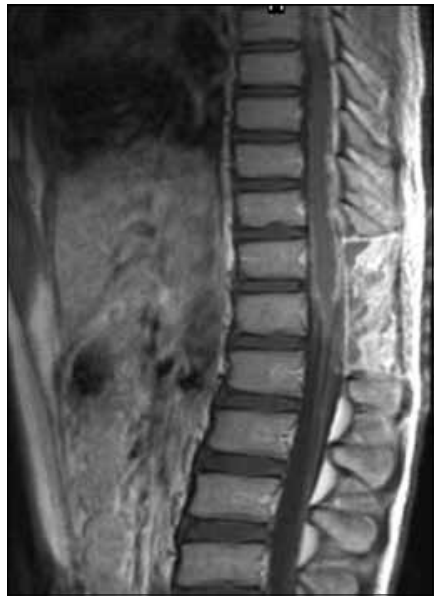

Figure 4c: Sagittal $(A, B)$ and axial $(C, D) T_{1}$-weighted magnetic resonance imaging of thoracic spine showing total excision of $T_{11}-T_{12}$ extradural mass compressing the cord and infiltrating the paraspinal area through the neural foramina

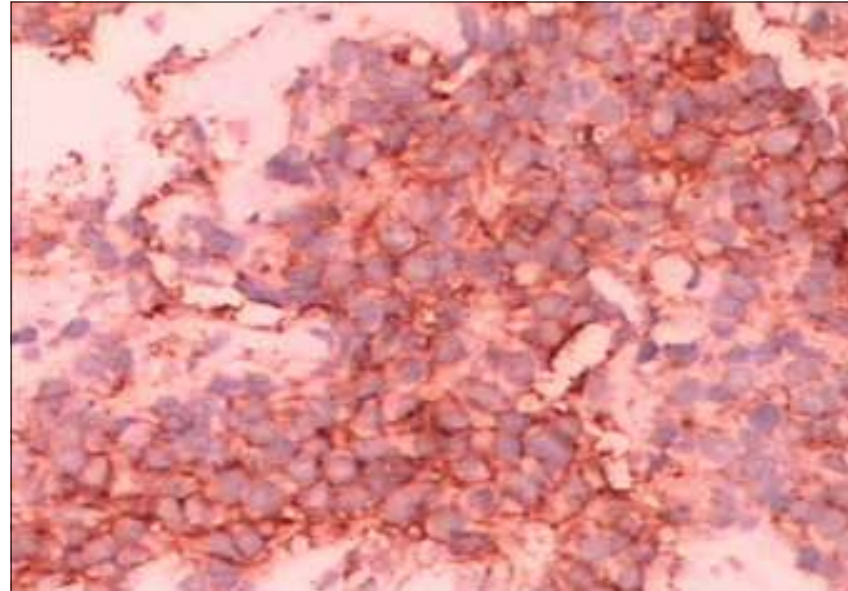

Figure 3h: Light microscopic photograph showing a typical highly cellular pPNET tumor consisting of undifferentiated small round cells with frequent mitoses(G) and CD99 immunoreactivity in pPNET tumor cells(H)

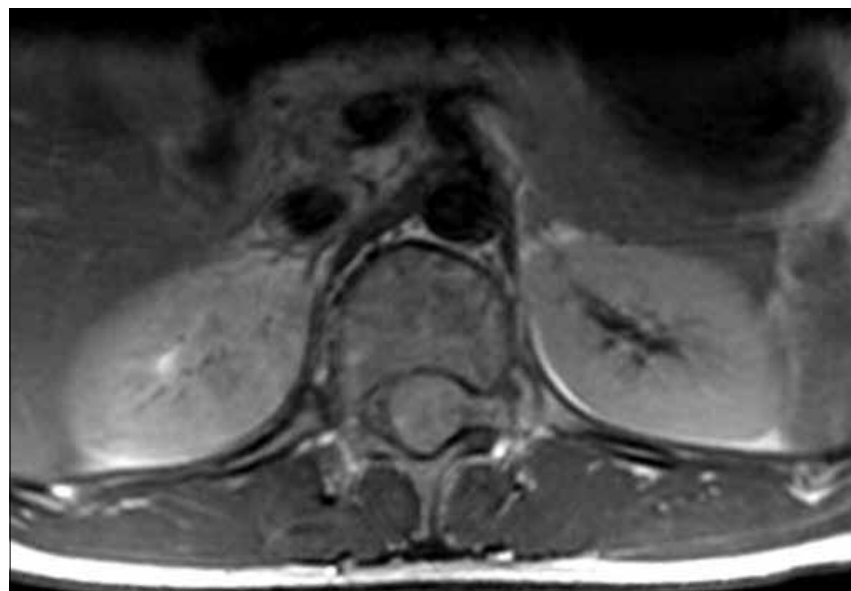

Figure 4b: Sagittal (A,B) and axial (C, D) $\mathrm{T}_{1}$-weighted magnetic resonance imaging of thoracic spine showing total excision of $\mathrm{T}_{11}-\mathrm{T}_{12}$ extradural mass compressing the cord and infiltrating the paraspinal area through the neural foramina

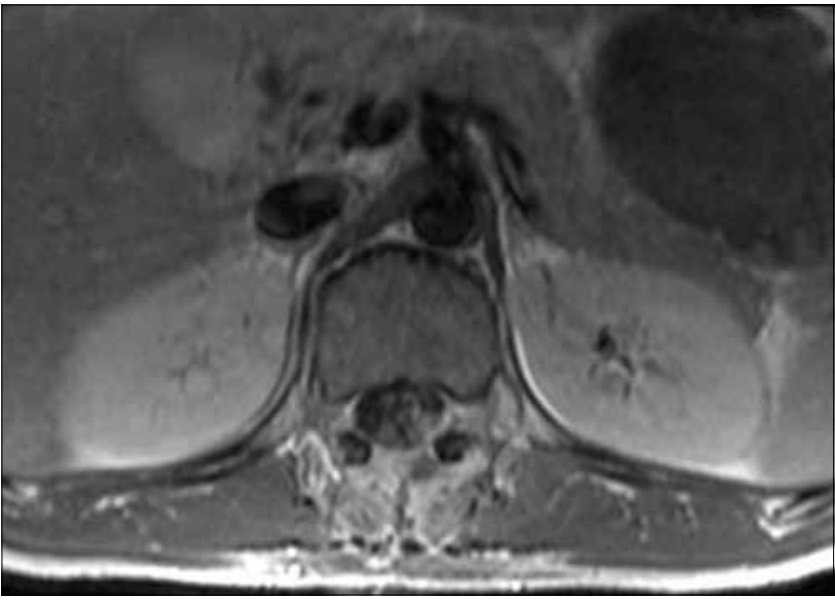

Figure 4d: Sagittal $(A, B)$ and axial $(C, D) T_{1}$-weighted magnetic resonance imaging of thoracic spine showing total excision of $T_{11}-T_{12}$ extradural mass compressing the cord and infiltrating the paraspinal area through the neural foramina 
months duration. The patient had become bedridden for seven days and had been urine and stool incontinent for six days. On physical examination, power in the lower limbs was grade $1 / 5$, and there was a hypoesthesia below $\mathrm{T}_{8}$ level. MRI showed an intradural extramedullary tumor at $\mathrm{T}_{11}-\mathrm{T}_{12}$ level compressing the cord. Through a $\mathrm{T}_{11}-\mathrm{T}_{12}$ laminectomy, an intradural extramedullary vascular lesion was noted encasing the nerve roots and conus [Figure $4 a$ and $b$ ]. At exploration, the intradural mass was subpial, soft and grayish. The mass was totally excised [Figure 4c and d]. Histopathology confirmed PNET. After surgical recovery, the patient received the same dose of radiotherapy and chemotherapy like in case 1 . The patient was able to walk unassisted at six months of follow-up.

\section{Discussion}

Intraspinal PNET is extremely rare. Recently in 2006 Kampman et al., had reviewed the clinical characters and genetics of 28 cases of intraspinal PNET reported in the literature. ${ }^{[5]}$ Since then 13 additional cases of intraspinal PNET have been reported. However, the histopathologic distinction between cPNET and pPNET has not been made in most of the reported cases. Kampman et al., ${ }^{[5]}$ had recently summarized the distinguishing features between cPNET and pPNET.

We summarized the clinical characteristics of the 45 cases, including our four cases, of intraspinal PNET reported till date in Tables 1 and 2. Intraspinal PNET has adult onset and male predominance. The average age at presentation for patients with intraspinal PNET was 24.1 years (range three months to 69 years) much higher than the average age for intracranial PNET, ${ }^{[7]}$ The duration of illness is often short, less than four months and it can be as short as four day seen in one (Case 2) of our patients. These tumors can occur at any levels of the spine and the location can be intramedullarily, intradural-extramedullarily or epidurally. Only 12 cases of pPNET with positive immunostaining for CD99 or PGP 9.5, have been reported and half of them were in the lumbar region. This might be due to the fact that the cauda equina forms part of the peripheral nervous system. Cranial symptoms are not a feature of primary intraspinal PNET. This is a feature that distinguishes primary intraspinal PNET from primary intracranial PNET with spinal metastasis. All our patients underwent cranial imaging postoperatively with no evidence of any pathology [Figure 1e,2e,3e and 4e]. MRI features are not specific for this lesion as was seen in our four cases.

The cPNET frequently disseminates via the cerebrospinal fluid and rarely metastasize out side the CNS, and pPNET may disseminate to distant sites. However,

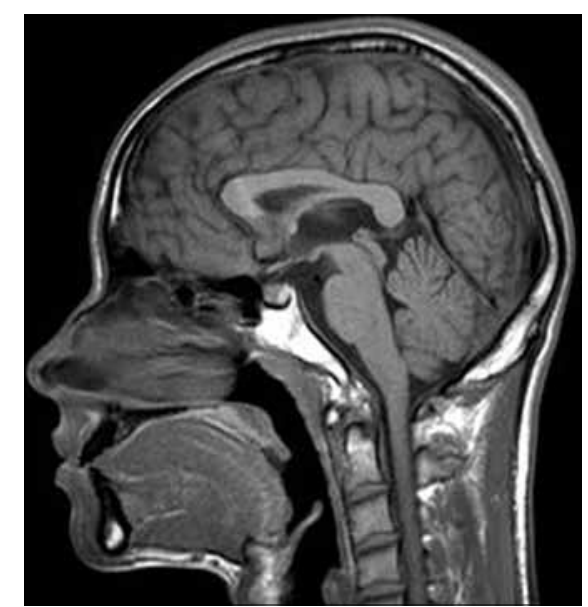

Figure 4e: Preoperative cranial magnetic resonance imaging showed that no other tumors were detected

intraspinal PNET is locally aggressive and local recurrences are common. Of the 33 patients with primary intraspinal cPNET [Table 1], 10 patients had metastasized to distant sites: Leptomeninges in two, lymph node in two, lung in two, pleura in one, and intracranial in 3 . Of the 12 patients with pPNET [Table 2], only one patient had metastazed to the cerebral hemisphere and we report the first case with distant vertebral metastasis (Case 3).

In all the reported cases the diagnosis was established by histopathology and immunohistochemistry. The characteristics diagnostic features of PNET by histopathology and immunohistochemistry include: (1) poorly differentiated small, round/spindle-shaped cells [Figure 3g]; (2) densely packed or in sheets or nests; (3) positive for neuronal or glial markers like neuron-specific enolase, CD99, synaptophysin, glial fibrillary acidic protein (GFAP), S-100, etc., Recent studies suggest that the expression of MIC2 glycoprotein by immunocytochemical staining (CD99) can help to differentiate between central and peripheral PNET. ${ }^{[5]}$ Similarly in situ hybridization analysis of mRNA expression for specific genes can be used to diagnose the PNET subtypes and plan optimal treatment protocol. ${ }^{[36]}$

In view of the limited number of reported cases, the optimal treatment for intraspinal PNET has not yet been defined. Surgical excession and decompression is the primary mode of treatment. Neurologic empovement is often noted in most of the patients following surgery. Craniospinal irradiation and hyperfractionated radiotherapy of the tumor region have been shown to be of benefit. ${ }^{[22]}$ Though there is no agreement on the chemotherapy regimens, successful results have been reported using combinations of cyclophosphamide or ifosfamide, cisplatin or 
Table 1: Demographic and clinical data of intraspinal central primitive neuroectodermal tumors

\begin{tabular}{|c|c|c|c|c|c|}
\hline Authors [Ref] & Age/sex (Years) & Level & Location & Metastases & Survival months \\
\hline Smith et al. [8] & $24 / M$ & Lumbar & Cauda equine & Lung & 10 \\
\hline Kosnik et al. [9] & NA/NA & Cervical & Unknown & None & NA \\
\hline Kosnik et al. [9] & NA/NA & Cervical & Unknown & None & NA \\
\hline Kosnik et al. [9] & NA/NA & Thoraco-lumbar & Unknown & Lung, bone, lymph node & NA \\
\hline Rodriquez et al. [10] & $16 / \mathrm{M}$ & - & - & - & - \\
\hline Kepes et al. [11] & $24 / M$ & Lumbar & Cauda equine & None & 18 \\
\hline Kepes et al. [11] & $56 / M$ & Lumbar & Cauda equine & None & Alive at 36 \\
\hline Kepes et al. [11] & $39 / M$ & Lumbar & Cauda equine & None & 42 \\
\hline Liu et al. [12] & $26 / F$ & Lumbo-sacral & Extradural & None & Alive at 6 \\
\hline Sevick et al. [13] & $26 / M$ & Cervical & Intradural, extramedullary & Pleura, bone & 36 \\
\hline Jaksche et al. [14] & $15 / F$ & Thoraco-lumbar & Intra- and extramedullary & None & 18 \\
\hline Jaksche et al. [14] & $26 / M$ & Thoraco-lumbar & Intra- and extramedullary & None & 36 \\
\hline Freyer et al.[15] & $7 / M$ & Thoraco-lumbar & Intramedullary & None & 20 \\
\hline Ogasawara et al. [16] & $16 / F$ & Lumbar & Intramedullary & Intracranial & 29 \\
\hline McDermott et al. [17] & $47 / M$ & Lumbar & Cauda equine & None & 16 \\
\hline $\begin{array}{l}\text { Kwon et al. [18] } \\
\text { (months) }\end{array}$ & $3 / F$ & Thoracic & Intramedullary & Intracranial & $<1$ \\
\hline Deme et al. [19] & $22 / F$ & Thoraco-lumbar & Intramedullary & None & Alive at 15 \\
\hline Koot et al. [20] & $2 / \mathrm{F}$ & Cervical & Extramedullary & None & 12 \\
\hline Papadatos et al. [21] & $23 / F$ & Thoracic & Intradural, extramedullary & None & 12 \\
\hline Virani and Jain [24] & $4 / \mathrm{M}$ & Thoracic & Extradural & None & Alive at 18 \\
\hline Mawrin et al. [26] & $69 / M$ & Thoracic & Intramedullary & None & \\
\hline Yuvaz et al. [25] & $18 / \mathrm{F}$ & Lumbar & Extramedullary & None & Alive at 25 \\
\hline Albrecht et al. [27] & $19 / F$ & Lumbar & Intradural, intra- & Local recurrence & 23 \\
\hline Mawrin et al. [26] & $22 / F$ & Thoracic & Extramedullary, intradural & Local recurrence & Alive at 9 \\
\hline Izycka et al. [28] & $26 / M$ & Cervical & Extraspinal, intrameningeal & Local recurrence & 3 \\
\hline Aydin et al. [30] & $14 / \mathrm{M}$ & Thoracic & Extradural & None & - \\
\hline Kampman et al. [5] & $2 / M$ & Cervical & Intramedullary & Local & 7 days \\
\hline Kumar et al. [33] & $9 / F$ & Thoracic & Extramedullary & None & Alive at 24 \\
\hline Kumar et al. [33] & $8 / M$ & Cervical & Extradural & Local recurrence & Recured at 6 months \\
\hline Kumar et al. [33] & $18 / \mathrm{M}$ & Holocord & Intramedullary & None & Alive at 6 weeks \\
\hline Nutman et al. [34] & $19 / F$ & Thoraco-lumbar & Intradural, extramedullary & None & Alive at 24 \\
\hline Musahl et al. [35] & $27 / M$ & Sacral & Extradural & & Alive at 24 \\
\hline Case 1 & $19 / F$ & Cervical & Intradural, extramedullary & None & Alive at 10 \\
\hline Case 4 & $14 / \mathrm{M}$ & Thoracic & Intradural, extramedullary & None & Alive at 6 \\
\hline
\end{tabular}

Table 2: Demographic and clinical data of intraspinal peripheral primitive neuroectodermal tumors

\begin{tabular}{|c|c|c|c|c|c|}
\hline Authors [Ref] & Age/sex (Years) & Level & Location & Metastases & Survival months \\
\hline Dorfmuller et al. [22] & $32 / \mathrm{M}$ & Sacral & - & Hemispheres & Alive at 29 \\
\hline Dorfmuller et al. [22] & $17 / M$ & Lumbar & Epidural and paraspinal & No & Alive at 23 \\
\hline Isotalo et al. [23] & $52 / \mathrm{M}$ & Lumbo-sacral & Intradural & No & Alive at 12 \\
\hline Albrecht et al. [27] & $29 / F$ & Thoracic & Intradural & Local recurrence & Alive at 17 \\
\hline Akyuz et al. [29] & $31 / M$ & Lumbar & Intradural, extramedullary & Local recurrence & - \\
\hline Weber et al. [32] & $26 / M$ & Lumbar & - & Local recurrence & Alive at 72 \\
\hline Kim et al. [31] & $17 / M$ & Thoraco-lumbar & Intramedullary & None & - \\
\hline Perry et al. [6] & $27 / M$ & Lumbar & Extradural & None & Alive at 72 \\
\hline Perry et al. [6] & $16 / \mathrm{F}$ & Lumbar & Extradural & None & Alive at 5 \\
\hline Case 2 & $46 / \mathrm{M}$ & Thoracic & Intradural, extramedullary & None & Alive at 14 \\
\hline Case 3 & $58 / \mathrm{M}$ & Thoracic & Extradural & Vertebrae & Alive at 25 \\
\hline
\end{tabular}

carboplatin, and vincristine-peplomycin. ${ }^{[19]}$ The chemotherapy protocol for cPNET should be different from that for pPNET, as the latter is more closely related to Ewing's sarcoma. Peripheral blood stem cell transfusion for PNET has been recently proposed. ${ }^{[37]}$ Three of our patients were treated with postoperative radiotherapy and chemotherapy, and all our patients are still alive and asymptomatic for 6-25 months. Despite the aggressive treatment with adjuvant radiotherapy and chemotherapy, most of the patients die within three years (range: 3 months-72 months). There is still a need for more clinical studies to explore reasonable strategies of treatment.

\section{References}

1. Brat DJ, Parisi JE, Kleinschmidt-DeMasters BK, Yachnis AT, Montine TJ, Boyer PJ, et al. Surgical neuropathology update: A review of changes introduced by the WHO classification of tumours of the central nervous system, $4^{\text {th }}$ edition. Arch Pathol Lab Med 2008;132:993-1007,

2. Hart MN, Earle KM. Primitive neuroectodermal tumors of the brain in children. Cancer 1973;32:890-7.

3. Nishio S, Morioka T, Fukui M. Primitive neuroectodermal tumors. Crit Rev Neurosurg 1998;8:261-8.

4. Dehner LP. Peripheral and central primitive neuroectodermal tumors. 
A nosologic concept seeking a consensus. Arch Pathol Lab Med 1986;110:997-1005.

5. Kampman WA, Kros JM, De Jong TH, Lequin MH. Primitive neuroectodermal tumours (PNETs) located in the spinal canal; the relevance of classification as central or peripheral PNET: Case report of a primary spinal PNET occurrence with a critical literature review. J Neurooncol 2006;77:65-72.

6. Perry R, Gonzales I, Finlay J, Zacharoulis S. Primary peripheral primitive neuroectodermal tumors of the spinal cord: Report of two cases and review of the literature. J Neurooncol 2007;81:259-64.

7. Hargrave DR, Zacharoulis S. Pediatric CNS tumors: Current treatment and future directions. Expert Rev Neurother 2007;7:1029-42.

8. Smith DR, Hardman JM, Earle KM. Metastasizing neuroectodermal tumors of the central nervous system. J Neurosurg 1969;31:50-8.

9. Kosnik EJ, Boesel CP, Bay J, Sayers MP. Primitive neuroectodermal tumors of the central nervous system in children. J Neurosurg 1978;48:741-6.

10. Rodriguez M, Dinapoli RP. Spinal cord compression: With special reference to metastatic epidural tumors. Mayo Clin Proc 1980;55:442-8.

11. Kepes JJ, Belton K, Roessmann U, Ketcherside WJ. Primitive neuroectodermal tumors of the cauda equina in adults with no detectable primary intracranial neoplasm—three case studies. Clin Neuropathol $1985 ; 4: 1-11$.

12. Liu HM, Yang WC, Garcia RL, Noh JM, Malhotra V, Leeds NE. Intraspinal primitive neuroectodermal tumor arising from the sacral spinal nerve root. J Comput Tomogr 1987;11:350-4.

13. Sevick RJ, Johns RD, Curry B.J. Primary spinal primitive neuroectodermal tumor with extraneural metastases. AJNR Am J Neuroradiol 1987;8:1151-2.

14. Jaksche H, Wöckel W, Wernert N. Primary spinal medulloblastomas? Neurosurg Rev 1988;11:259-65.

15. Freyer DR, Hutchinson RJ, McKeever PE. Primary primitive neuroectodermal tumor of the spinal cord associated with neural tube defect. Pediatr Neurosci 1989;15:181-7.

16. Ogasawara H, Kiya K, Kurisu K, Muttaqin Z, Uozumi T, Sugiyama K, et al. Intracranial metastasis from a spinal cord primitive neuroectodermal tumor: Case report. Surg Neurol 1992;37:307-12.

17. McDermott VG, el-Jabbour JN, Sellar RJ, Bell J. Primitive neuroectodermal tumour of the cauda equina. Neuroradiology 1994;36:228-30

18. Kwon OK, Wang KC, Kim CJ, Kim IO, Chi JG, Cho BK. Primary intramedullary spinal cord primitive neuroectodermal tumor with intracranial seeding in an infant. Childs Nerv Syst 1996;12:633-6.

19. Deme S, Ang LC, Skaf G, Rowed DW. Primary intramedullary primitive neuroectodermal tumor of the spinal cord: Case report and review of the literature. Neurosurgery 1997;41:1417-20.

20. Koot RW, Henneveld HT, Albrecht KW. Two children with unusual causes of torticollis: Primitive neuroectodermal tumor and Grisel's syndrome. Ned Tijdschr Geneeskd 1998;142:1030-3.

21. Papadatos D, Albrecht S, Mohr G, del Carpio-O'Donovan R. Exophytic primitive neuroectodermal tumor of the spinal cord. AJNR Am J Neuroradiol 1998;19:787-9.

22. Dorfmüller G, Würtz FG, Umschaden HW, Kleinert R, Ambros PF. Intraspinal primitive neuroectodermal tumour: Report of two cases and review of the literature. Acta Neurochir (Wien) 1999;141:1169-75.
23. Isotalo PA, Agbi C, Davidson B, Girard A, Verma S, Robertson SJ. Primary primitive neuroectodermal tumor of the cauda equina. Hum Pathol 2000;31:999-1001.

24. Virani MJ, Jain S. Primary intraspinal primitive neuroectodermal tumor (PNET): A rare occurrence. Neurol India 2002;50:75-80.

25. Yavuz AA, Yaris N, Yavuz MN, Sari A, Reis AK, Aydin F. Primary intraspinal primitive neuroectodermal tumor: Case report of a tumor arising from the sacral spinal nerve root and review of the literature. Am J Clin Oncol 2002;25:135-9.

26. Mawrin C, Synowitz HJ, Kirches E, Kutz E, Dietzmann K, Weis S. Primary primitive neuroectodermal tumor of the spinal cord: Case report and review of the literature. Clin Neurol Neurosurg 2002;104:36-40.

27. Albrecht CF, Weiss E, Schulz-Schaeffer WJ, Albrecht T, Fauser S, Wickboldt J, Primary intraspinal primitive neuroectodermal tumor: Report of two cases and review of the literature. J Neurooncol 2003;61:113-20.

28. Izycka-Swieszewska E, Debiec-Rychter M, Wasag B, Wozniak A, Gasecki D, Plata-Nazar K, et al. A unique occurrence of a cerebral atypical teratoid/rhabdoid tumor in an infant and a spinal canal primitive neuroectodermal tumor in her father. J Neurooncol 2003;61:219-25.

29. Akyüz M, Demiral AN, Gürer IE, Uçar T, Tuncer R. Primary primitive neuro-ectodermal tumor of cauda equina with intracranial seeding. Acta Neurochir (Wien) 2004;146:525-8.

30. Aydin MV, Sen O, Ozel S, Kayaselcuk F, Caner H, Altinors N. Primary primitive neuroectodermal tumor within the spinal epidural space: Report of a case and review of the literature. Neurol Res 2004;26:774-7.

31. Kim YW, Jin BH, Kim TS, Cho YE. Primary intraspinal primitive neuroectodermal tumor at conus medullaris. Yonsei Med J 2004;45:533-8.

32. Weber DC, Rutz HP, Lomax AJ, Schneider U, Lombriser N, Zenhausern R, et al. First spinal axis segment irradiation with spot-scanning proton beam delivered in the treatment of a lumbar primitive neuroectodermal tumour. Case report and review of the literature. Clin Oncol (R Coll Radiol) 2004;16:326-31.

33. Kumar R, Reddy SJ, Wani AA, Pal L. Primary spinal primitive neuroectodermal tumor: Case series and review of the literature. Pediatr Neurosurg 2007;43:1-6.

34. Nutman A, Postovsky S, Zaidman I, Elhasid R, Vlodavsky E, Kreiss Y, et al. Primary intraspinal primitive neuroectodermal tumor treated with autologous stem cell transplantation: Case report and review of the literature. Pediatr Hematol Oncol 2007;24:53-61.

35. Musahl V, Rihn JA, Fumich FE, Kang JD. Sacral intraspinal extradural primitive neuroectodermal tumor: A case report. Spine J 2008;8:1024-9.

36. Izycka-Swieszewska E, Stefanowicz J, Debiec-Rychter M, Rzepko R, Borowska-Lehman J. Peripheral primitive neuroectodermal tumor within the spinal epidural space. Neuropathology 2001;21:218-21.

37. Pérez-Martínez A, Lassaletta A, González-Vicent M, Sevilla J, Díaz MA, Madero L. High-dose chemotherapy with autologous stem cell rescue for children with high risk and recurrent medulloblastoma and supratentorial primitive neuroectodermal tumors. J Neurooncol 2005;71:33-8.

Accepted on 02-07-2009

Source of Support: Nil, Conflict of Interest: None declared. 